Proceed ings of the $35^{\text {th }}$ Intemational Conference

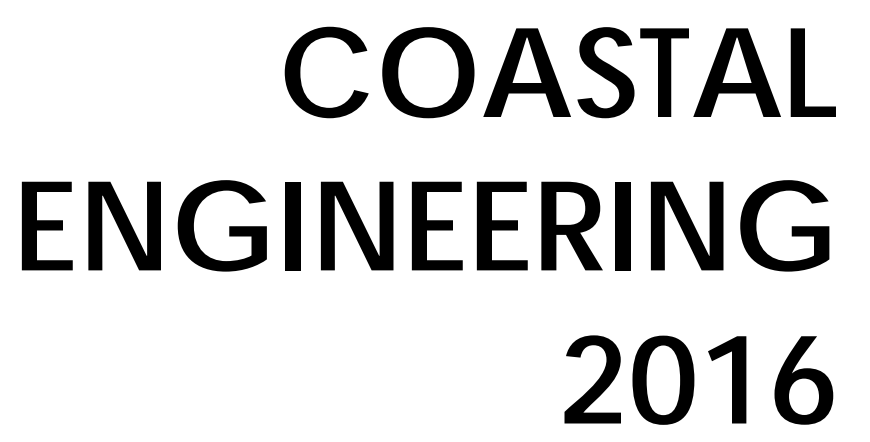

17 November - 20 November, 2016 Antalya, Turkey 


\section{MESSAGE FROM THE LOCAL ORGANIZING COMMITTEE}

The $35^{\text {th }}$ ICCE Conference took place in Antalya, over 17-20 November, 2016. We do believe that ICCE 2016 supported by the Turkish Chamber of Civil Engineers, organized under the auspices of the Coastal Engineering Research Council (CERC) of Coasts, Oceans, Ports and Rivers Institute (COPRI) of the American Society of Civil Engineers (ASCE), had a great impact nationally and globally, strengthened the bonds of knowledge in the field of Coastal Engineering, and reflected the colors of different cultures in addition to enriching the experience of young engineers and students.

ICCE 2016, Istanbul was to be held in between 17-21 July, but was forced to be postponed to due to unpredictable events which took place in Turkey, beyond our control. During all these difficult times, we had no intention to yield under the pressure of these events. Therefore, we, the Local Organizing Committee (LOC) considered all viable alternatives, respecting the views of all parties involved, namely CERC, COPRI of ASCE, and the Turkish Chamber of Civil Engineers and the participants. We felt professionally and ethically committed to proceed regardless and to make ICCE happen. The LOC made the final decision about the new venue and date of the ICCE 2016. Accordingly, the postponed ICCE, 2016 was held in Mardan Palace Hotel, in Antalya over 17-20 November, 2016. We have to note that we do appreciate the support of the CERC and COPRI of ASCE during our journey from Istanbul to Antalya and COPRI secretary Prof. Dr. Patrick Lynett. We extend our gratitude to Antalya Metropolitan Municipality for their very valuable support and we are also thankful to our sponsors for their continuing valuable support. On the other hand, we duly noted and fully understood the hesitation of shown by some of the participants who could not attend the conference.

From 26 different countries, 210 participants, including students and guests, attended the ICCE 2016, Antalya. Invited key note speakers, namely Prof. Dr. R. Dalrymple, Prof. Dr. M. Sumer, Prof. Dr. J. van der Meer, Prof. Dr. C. Synolakis, Prof. DR. S. Takahashi, who were also members of scientific committee and Prof. Dr. N.Kobayashi as chair of ICCE 2018, with their lectures in the opening ceremony and in the respective plenary sessions contributed significantly to the achievement of the goals and the success of the conference.

The quality of the papers presented, the discussions in the sessions, and also the interaction between the participants contributed greatly to make the conference a success.

The Early Career Scientist Event (ECSE) was planned within the ICCE 2016 to provide a specific time and place in the conference schedule where the early career attendees could meet with each other and discuss their research work in a comfortable and informal setting. The event was held on Thursday (November 17, 2016) after the conference sessions and around 50 young researchers attended the event. The resulting networking among the participants was very successful as the group was small, which enabled everyone to meet each other and all could talk about their experiences in detail. 
We have no doubt that this meeting was a valuable opportunity to be a part of the scientifically enriched environment of coastal engineering, not to mention items such as the historical beauties of magnificent Antalya and Turkish hospitality.

On behalf of the Local Organizing Committee of ICCE 2016, we extend our special thanks to the Chamber of Turkish Civil Engineers ; Cemal Gokce (Chair), Aysegül Bildirici Suna (member) and Cem Oğuz (member), Antalya Branch of Chamber of Turkish Civil Engineers; Mustafa Balci (Chair) and finally Members of Technical Committee ; Yalcın Arisoy, Berna Burak Aydogan, Burak Aydogan, Cuneyt Baykal, Serdar Beji, Hulya K. Cihan, Yeşim Celikoglu, Mustafa Esen, H.Gokhan Guler, Anil A. Güler, Utku Kanolu, V.S. Ozgur Kırca, Dogan Kisacik, Bergüzar O. Ozbahçeci, Mehmet Ozturk, Ilgar Safak, Cihan Sahin, Gulizar O. Tarakcioğlu,Tugçe Yüksel,

Last but not the least, we thank to Mayor of Antalya Metropolitan Municipality Menderes Turel for his interest and valuable support to the Conference.

On behalf of the Local Organizing Committee of ICCE 2016 we had the pleasure and excitement of welcoming you in Antalya at ICCE 2016. The prestigious conference series will continue with ICCE 2018, Baltimore (USA) and ICCE 2020 Sidney, (Australia).

With warm regards,

Prof. Dr. Aysen Ergin (Chairperson)

Prof. Yalcin Yüksel (Co -chair)

Prof. Ahmet C. Yalciner( Co-chair)

Isikhan Güler (executive member)

Esin Cevik (Executive member) 